\title{
Avaliando a Inserção de Egressos de Cursos de Graduação da Área de Tecnologia da Informação no Mercado de Trabalho Regional Brasileiro. Um Estudo em Campi de Cidades do Interior
}

\author{
Evaluating the Admission of Graduates of Information \\ Technology Courses on Brazilian Regional Labor Market. \\ A Study in Campi of Cities of Interior
}

\author{
Maria Simone Mendes Nunes \\ Alberto Sampaio Lima * \\ Wagner Bandeira Andriola, \\ João Fereira de Lavor \\ Francisco Erivelton Fernandes de Aragão \\ Universidade Federal do Ceará (UFC)
}

\begin{abstract}
A política de expansão das universidades brasileiras para o interior foi uma tendência nos últimos anos. O presente artigo apresenta os resultados de uma investigação que avaliou o processo de inserção laboral de egressos dos cursos da área de Tecnologia da Informação (TI) dos campi de interior da Universidade Federal do Ceará (UFC). Foram identificadas as facilidades e dificuldades que os 102 egressos respondentes (68,9\% do universo) encontraram ante o mundo do trabalho, revelando uma dificuldade para a inserção laboral nos mercados regionais. A principal contribuição do trabalho foi a análise da estreita relação entre universidade, qualificação profissional, mercado de trabalho e desenvolvimento regional.
\end{abstract}

Palavras chave: Ensino Superior, Egressos, Tecnologia da informação, Inserção laboral, Desenvolvimento regional.

The expansion of Brazilian universities policy for the interior has been a trend in recent years. This paper presents the results of a study that evaluated the job placement of graduates from Information Technology (IT) undergraduate courses of the Federal University of Ceará (UFC), Brazil. We identified which facilities and difficulties that 102 graduates surveyed (68.9\% of the universe) met at the labor world and our results indicated the difficulty of labor insertion in regional markets. This research sought to contribute to the analysis of the close relationship between university, vocational training, labor market and regional development.

Keywords: Higher education, Graduates, Technology of information, Labor insertion, Regional development.

*Contacto: albertosampaio@ufc.br

issn: 1989-0397

www.rinace.net/riee/

https://revistas.uam.es/riee
Recibido: $\quad 17$ de octubre de 2016

$1^{\text {a }}$ Evaluación: 21 de marzo de 2017

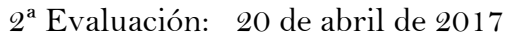

Aceptado: 18 de mayo de 2017 


\section{Introdução}

O mercado de trabalho atual tem demandado uma maior qualificação profissional da mão de obra em geral, fato que tem gerado uma demanda pela formação de bons profissionais de nível superior ou técnico. Entretanto, para que essa demanda possa ser cumprida e aconteça o ingresso e/ou permanência dos profissionais formados no mercado de trabalho, existe a necessidade de oferta de cursos de graduação que possam suprir necessidades locais, regionais, nacionais ou mesmo internacionais. No que concerne ao ensino superior brasileiro, políticas de governo para expansão de vagas têm sido intensificadas nos últimos anos, especialmente a partir de 2007, com a implementação do Programa de Apoio a Planos de Reestruturação e Expansão das Universidades Federais (REUNI), que teve como principal objetivo ampliar o acesso e a permanência na educação superior (BRASIL, 2007). A interiorização das Universidades Públicas brasileiras foi uma das consequências dessa política, conforme destacaram Andriola e Suliano (2015).

Existe uma crescente demanda por mão de obra qualificada na área de Tecnologia da Informação (TI), por se tratar de uma área de conhecimento recente e específica e, ainda, escassa. O estudo "Habilidades em Redes e Conectividade na América Latina" (Networking Skills Latin America), realizado pela empresa Cisco Systems, companhia multinacional na área de TI sediada nos Estados Unidos, analisou a disponibilidade de profissionais capacitados em TI entre os anos 2011 e 2015 em diversos países da América Latina. No Brasil, a lacuna de profissionais em 2011 foi de aproximadamente 39.900 trabalhadores, o equivalente a $20 \%$ entre oferta e demanda de mão de obra. $\mathrm{O}$ estudo prospectou que o mercado de TI deveria crescer cerca 12\% entre 2011 a 2015 (Cisco Systems, 2015).

Nesse contexto, a presente pesquisa teve como lócus avaliar a inserção laboral dos egressos de cursos dos campi de interior da Universidade Federal do Ceará (UFC), os quais ofertam cursos de graduação na área de Tecnologia da Informação (TI). Foram avaliados os campi de Quixadá e Sobral, pelo fato de serem os únicos campi de interior que atualmente possuem egressos de cursos dessa área. A questão de pesquisa foi a seguinte: como se dá a inserção laboral dos alunos egressos dos cursos de Tecnologia da Informação (TI) dos campi da UFC do interior do Ceará?

$\mathrm{Na}$ segunda seção deste artigo são apresentados os referenciais teóricos que fundamentaram a presente pesquisa, enquanto na seção 3 são descritos os procedimentos metodológicos do estudo realizado. Os resultados obtidos são analisados e discutidos na quarta seção. As considerações finais são apresentadas na seção 5 .

\section{Revisão de literatura}

Discussões acerca da formação docente têm-se feito presentes diante da sociedade atual para qual, em tese, deveria estar direcionada, assim como as requisições da Lei de Diretrizes e Bases, dos Parâmetros Curriculares Nacionais e das Orientações Curriculares para o Ensino Médio que suscitam questionamentos sobre como essa formação tem sido gerida nas mais diversas instituições formadoras. Logo, pesquisas feitas por diferentes estudiosos como Almeida Filho (1998); Moita Lopes (1999); Vieira 
Abrahão (2000/2001); Celani (2003) assinalam que essa formação possui restrições de ordem teórica - metodológica que necessitam ser debatidas.

A inserção laboral de egressos envolve diversos aspectos que devem ser avaliados. Botello et al. (2015) avaliou aspectos relacionados ao projeto de um curso de graduação, a partir da visão dos estudantes, além do perfil de ensino dos professores, métodos de ensino e avaliação, auto avaliação dos estudantes, serviços de suporte, habilitação e infraestrutura. Tais fatores impactam na qualidade dos cursos ofertados, e consequentemente, na qualidade da mão de obra que entra no mercado de trabalho.

De acordo com Garcés e Riquelme (2014), muitas das esperanças dos países em desenvolvimento estão na base de seus sistemas de ensino, e por essa razão existe uma necessidade urgente de se adaptar a oferta de educação em relação às demandas reais. $\mathrm{Na}$ medida em que a massificação do acesso ao ensino superior envolve uma reconfiguração do sistema de ensino e o mercado de trabalho de um país é resultante da análise de interesse em relação aos perfis ocupacionais, as diferenças entre um conjunto de carreiras profissionais de nível superior em diferentes áreas de conhecimento, ofertadas por universidades e institutos profissionais, refletem nas escolhas das várias opções de carreira no mercado de trabalho. Apesar da existência de um aumento significativo na taxa de graduados, como resultado da massificação do sistema de ensino superior profissional no Chile, em algumas carreiras, o grande volume de novos graduados não atendia às necessidades do mercado de trabalho. Os autores identificaram em sua pesquisa que a formação recebida no Chile era valorizada de acordo com sua natureza, tipo de carreira e pela instituição onde se estudava. Esses fatores não só afetavam os níveis de renda, mas também influenciavam a avaliação feita das carreiras e os salários a nível interno e externo, tornando a escolha do que estudar e onde estudar uma decisão não trivial.

Aparicio et al. (2016) afirmam que um dos principais critérios que definem a qualidade da Universidade consiste em sua articulação com o mercado de trabalho, ou seja, com o sistema de produção. Essa articulação é muito importante, sendo a resposta do ensino universitário às necessidades contextuais. Considera-se ainda como critérios de qualidade, a eficácia educacional, a eficiência econômica e a eficácia política. No entanto, apesar da articulação com o mercado ser crucial para a realização profissional e desenvolvimento regional e nacional, a pesquisa sobre o tema ainda é modesta. Não se conhecer quais os fatores que exercem maior impacto na formação do egresso e sua inserção no mercado de trabalho, dificulta a realização de mudanças que possam melhorar o que for viável a médio prazo. Os autores identificaram em sua pesquisa que o alinhamento entre o nível acadêmico e profissional é um fator primordial, estando ligado aos níveis mais altos de realização profissional dos egressos. As competências sociais influenciam nas possibilidades de sucesso dos egressos e os fatores importantes para o sucesso e realização profissional não são treinados de forma suficiente, por conta dos diferentes cenários (unidades acadêmicas, carreiras, empresas). Os autores ainda afirmam que sem uma associação entre teoria e prática na vida diária, dificilmente o desenvolvimento profissional que se deseja realizar na Universidade será atingido.

No estudo efetivado com 586 egressos de cursos de graduação de uma universidade pública federal, Andriola (2014) focou a obtenção de informações acerca: (a) da situação laboral; (b) do grau de satisfação com a área de inserção laboral e com a remuneração; (c) 
das opiniões a respeito da adequação do currículo às expectativas pessoais e às demandas do mercado de trabalho; (d) da necessidade de aprimorar a formação recebida no âmbito da graduação. Os resultados identificaram elevada proporção de egressos inseridos no mercado de trabalho, atuando na mesma área de formação e com renda mensal individual variando de 1,5 a três salários mínimos. Ademais, os resultados proporcionaram informações sobre o reconhecimento majoritário dos egressos quanto à qualidade: (i) da formação recebida; (ii) da gestão acadêmica do curso; (iii) da adequação curricular para o exercício profissional; (iv) do estágio curricular obrigatório; (v) das salas de aula e espaços de convivência.

Conforme asseverado por Lima e Andriola (2013), o relato de práticas pedagógicas inovadoras tem ajudado os docentes das instituições de ensino superior, contribuindo para a melhoria do ensino de graduação, através da obtenção de melhores resultados no processo de ensino e aprendizagem. Este aspecto abordado que exerce impacto direto sobre as tecnologias adotadas no processo de ensino e aprendizado pode ser considerado como elemento que contribui para a qualidade da mão de obra egressa dos cursos de graduação, conforme destacaram Lima, Andriola e Tavares (2015).

De acordo com Vinogradov (2017), existe um número crescente de pesquisas em novos indicadores e medidas, que abordam o desempenho dos cursos ofertados pelas universidades, cujos resultados podem ser utilizados na avaliação institucional dessas instituições de ensino superior. Em sua pesquisa, os autores apresentaram estudo realizado na Universidade Szent István, Hungria, sobre a inserção laboral de egressos de cursos de bacharelado e mestrado no mercado de trabalho. Os resultados indicaram que os egressos pesquisados estavam satisfeitos com as circunstâncias pessoais e conteúdo do seu trabalho, e menos satisfeitos com suas oportunidades de desenvolvimento profissional e de carreira, bem como com seus salários. Os egressos com maior titulação (mestrado) e os que tiveram experiência de trabalho durante a formação, obtiveram uma maior facilidade para o ingresso no mercado de trabalho após a finalização do curso. A presente pesquisa difere desse trabalho, por abordar a inserção laboral regional, tendo tido foco específico nos egressos de cursos de graduação da área de tecnologia da informação (TI).

Nesse âmbito, convém salientar, por oportuno, que as universidades sempre tiveram grande importância para o desenvolvimento de economias, de países, de continentes. Por conta dessa importância a implantação de uma nova universidade em uma região carente de Ensino Superior pode ser um grande acontecimento e impulsionar possibilidades de desenvolvimento (Andriola, 2011).

Segundo Rolim (2009), a presença da universidade nas regiões é importante no que se refere à qualificação da força de trabalho, ao efeito gerado por suas pesquisas para o aumento da produtividade, à solução de problemas locais, ao aumento do nível geral de conhecimento e de cultura da região, à sua contribuição enquanto lócus de inovação e de constituição de cidadania.

Ou seja, a contribuição que uma universidade pode ter no desenvolvimento econômico de uma região passa por diversos elementos que vão desde a qualificação do trabalhador até um nível mais geral de conhecimento e de construção da cidadania (Andriola \& Suliano, 2015). 
A partir do intenso processo de globalização, não apenas os grandes centros são importantes para o desenvolvimento econômico. É necessário monitorar e incentivar o desenvolvimento de economias regionais. Rolim (2009) ressalta que a dimensão regional passa a ter uma importância capital na medida em que o ambiente regional/ local é tão importante quanto a situação macroeconômica nacional na determinação da habilidade das empresas em competir numa economia globalizada, ou seja, a disponibilidade dos atributos regionais/locais (conhecimento, habilidades, etc.) influirá fortemente na decisão locacional das empresas, o que faz das universidades regionalmente engajadas peças-chave das regiões onde estão inseridas.

A região que está bem desenvolvida ou em processo de crescimento apresenta possibilidade de geração de emprego e renda, atrai empresas, impulsiona a economia como um todo. Ainda, para Rolim (2009), nessa perspectiva, as universidades podem desempenhar um papel determinante no desenvolvimento de economias regionais, sendo possível distinguir dois tipos de intervenção: a da universidade que está na região e a da que é da região. Na primeira, a universidade simplesmente se localiza na região, se caracteriza por um reduzido número de vínculos e compromissos com a região e com o seu desenvolvimento e o produto do seu trabalho está direcionado para o contexto nacional e/ou internacional. Já na segunda trajetória, a universidade demonstra ter um forte impacto no processo de desenvolvimento regional, estabelece vínculos e compromissos intensos com o futuro da região e o produto do seu trabalho, além de ter como referência a qualidade acadêmica universal, está voltado para a superação das questões da região. Essa distinção entre ser e estar na região faz toda a diferença para o desenvolvimento regional.

Esse impacto das universidades no desenvolvimento regional pode ser investigado sob diferentes aspectos: políticos, sociais, econômicos, etc, que não caberiam em uma única pesquisa. $\mathrm{O}$ foco da presente pesquisa foi a análise do desenvolvimento regional sob a ótica da inserção laboral e sobre o mercado de trabalho de Tecnologia da Informação (TI).

O campo de estudo desta pesquisa foi inspirado a partir da política de expansão do Ensino Superior, a qual levou campi avançados da Universidade Federal do Ceará (UFC) a regiões interioranas do estado. A implementação destes campi trouxe a possibilidade de maior crescimento e melhoria da economia local e regional.

Nas últimas décadas, a sociedade vem passando por várias mudanças na forma de ver o mundo e nas formas de interação entre as pessoas. $\mathrm{O}$ mundo virtual está cada vez mais presente na vida real, a tecnologia está no cotidiano do homem. O que era novo se torna antiquado em pouco tempo, devido à contribuição de um dos elementos mais presentes e mais influentes da contemporaneidade que é a informação. As conclusões do trabalho de Castells (1999) confirmam o papel decisivo desempenhado pelos meios de inovação no desenvolvimento da revolução da Tecnologia da Informação: concentração de conhecimentos científicos/tecnológicos, instituições, empresas e mão-de-obra qualificadas são as forjas da inovação da Era da Informação.

Castells (1999) afirma que para a era da Informação acontecer é importantíssimo que ciência e tecnologia caminhem juntas e que a qualificação profissional seja efetivamente realizada. Para o autor, o paradigma da Tecnologia da Informação não evolui para seu fechamento como um sistema, mas rumo a abertura como uma rede de acessos múltiplos. 
É forte e impositivo em sua materialidade, mas adaptável e aberto em seu desenvolvimento histórico. Abrangência, complexidade e disposição em forma rede são seus principais atributos".

Ou seja, esta nova sociedade regida prioritariamente pela informação está em constante mudança, permite múltiplas possibilidades de acessos, não para. Na Educação não é diferente. Há a necessidade de formação de profissionais para lidarem com essa nova perspectiva de mundo, de comunicação e de informação. É nesta perspectiva que se torna primordial a qualificação de profissionais na área de Tecnologia da Informação (TI). Isto é, há uma nova configuração nas relações tanto pessoais como de mercado de trabalho que exigem reformulações e atualizações capazes de tornar os novos profissionais aptos a lidarem com estas novas relações e tratem a informação como algo primordial.

Chaui (2003) afirma que devido ao fato da universidade ter passado historicamente do conceito de uma instituição social para o conceito de organização social, houve uma quebra de paradigmas, onde suas ações deixaram de ser articuladas às ideias de reconhecimento externo e interno, de legitimidade interna e externa, passando a ter foco nas operações definidas como estratégias balizadas pelas idéias de eficácia e de sucesso no emprego de determinados meios para alcançar o objetivo particular que a define. De acordo com o autor, essa nova visão de universidade, denominada operacional, está estruturada por estratégias e programas de eficácia organizacional e, portanto, pela particularidade e instabilidade dos meios e dos objetivos. O autor ainda afirma que na atual sociedade do conhecimento, na medida em que, na forma atual do capitalismo, a hegemonia econômica pertence ao capital financeiro e não ao capital produtivo, a informação prevalece sobre o próprio conhecimento, uma vez que o capital financeiro opera com riquezas puramente virtuais, cuja existência se reduz à própria informação. Do ponto de vista da informação, a sociedade do conhecimento seria regida pela lógica do mercado (sobretudo o financeiro). O trabalho apresenta uma reflexão, apresentando argumentos que vão de encontro a atual tendência de integração entre a formação universitária e o mercado.

$\mathrm{Na}$ presente pesquisa, foi possível identificar que as atuais políticas públicas brasileiras tem defendido a visão que apregoa a necessidade de uma formação universitária mais integrada às necessidades do mercado, como visto na Lei de Diretrizes e Bases e Parâmetros Curriculares Nacionais.

A Associação Brasileira de Empresas de Tecnologia da Informação e Comunicação (BRASSCOM) estima que o mercado nacional emprega, atualmente, 1,2 milhão de profissionais, sendo cerca de $400 \mathrm{mil}$ em empresas de TIC e cerca de $800 \mathrm{mil} \mathrm{em}$ empresas de outros setores econômicos. Até 2016 esse número deve aumentar em 30\%. Além disso, a associação estima que cerca de 50 mil vagas estão desocupadas por conta da falta de profissionais qualificados para a área. (CSTIC, 2011).

Com referência à distribuição geográfica destas vagas há, ainda, grande fluxo de empresas na área e de empregos, concentrado nas regiões sul e sudeste do país. No ano de 2013, por exemplo, o setor contratou 159 mil pessoas no Brasil. Quase metade das vagas foi para o estado São Paulo (47\%), depois Rio de Janeiro (11\%) e Minas Gerais $(10 \%)$. Já os três estados da região sul empregaram em 2013 mais de 34 mil pessoas na área, sendo o Paraná o Estado com mais vagas e mais empresas. Apesar de 2016 ter uma 
estimativa crescimento modesto, a área de TIC deve crescer em torno de 2,6\%, (Internet Data Center, 2016).

Dados do Cadastro Geral de Empregos e Desempregados (CAGED), divulgado pelo Sindicato de Empresas de Informática (SINDINFO), também apontam que apesar de um momento econômico de recessão "o setor de Tecnologia da Informação registrou resultado positivo do emprego formal com 3.319 mil novos postos entre janeiro e julho de 2015, isto é, o número de contratações foi maior do que o número de demissões". (sindicato das empresas de informática, 2015). Apesar desse cenário de empregabilidade relativamente favorável na área de Tecnologia da Informação há de se questionar se essa gama de oportunidades atinge os profissionais recém-formados e se, no caso do estado do Ceará, e mais precisamente dos campi da UFC no interior do Estado, se os profissionais formados têm acesso ao trabalho e como se dá esse acesso.

Rocha (2015) afirma que "Conhecer melhor o perfil da mão-de-obra e as condições para qualificação dos trabalhadores na área da Tecnologia da Informação é muito importante para subsidiar políticas de formação congruentes com as demandas do mercado de trabalho” (p. 595). Não há como formar profissionais da área de Tecnologia da Informação (TI) com ferramentas e recursos desatualizados. Se a qualificação pode ser abordada como o conjunto de habilidades relativas ao trabalho (trabalho simples, complexo) associadas a um ofício, com a sofisticação de tais habilidades, cada vez mais se acentua a necessidade de formação profissional, estreitando as alianças do mercado de trabalho com o sistema de ensino.

Mundo do trabalho e sistemas de ensino precisam estar conectados para que a formação seja ofertada de forma que os egressos possam ter oportunidades reais no mercado de trabalho. Trabalhos relacionados ao tema da inserção laboral de egressos de cursos de graduação, tais como os de Miranda, Pazzelo e Lima (2014) e Macedo (2011), contribuem bastante para esta discussão e podem dar apontamentos para melhorias da qualificação ofertada.

Em suma, existem grandes desafios para os profissionais da área de Tecnologia da Informação (TI), especialmente, a atualização constante, valorização da mão de obra qualificada em nível superior. Esse desafio também existe para os cursos de graduação que necessitam se solidificarem e se expandirem como resultado das novas demandas do ensino e da sociedade como um todo.

\section{Procedimentos metodológicos}

O objetivo geral desta pesquisa foi investigar como se deu o processo de inserção laboral de egressos dos cursos de Tecnologia da Informação (TI) dos campi de interior da Universidade Federal do Ceará (UFC). Os objetivos específicos foram verificar se os egressos dos cursos de Tecnologia da Informação (TI) dos campi da UFC no interior estão sendo absorvidos pelo mercado de trabalho da região onde cada campus se localiza; identificar onde os egressos dos cursos de Tecnologia da Informação dos campi de interior da UFC estão conseguindo emprego, independente da sua região de formação; investigar possíveis dificuldades e/ou desafios e oportunidades que os jovens egressos encontram no processo de inserção no mercado de trabalho. 
Pelo fato da natureza da investigação avaliativa ter abordado as opiniões dos envolvidos sobre sua inserção laboral, empregou-se na avaliação o método ex post-facto (Bisquerra, 2004). A metodologia da presente pesquisa teve caráter quali-quantitativo, partindo de uma pesquisa exploratória, inicialmente, e em seguida descritiva. O instrumento de coleta de dados utilizado foi o questionário, composto de perguntas abertas e fechadas, sendo que para algumas perguntas fechadas foi adotada a escala de Likert. As perguntas que contém essa escala foram utilizadas para verificação da consistência interna do questionário sob o viés do coeficiente Alfa de Cronbach. Já para tratamento e análise de dados, foi utilizado o viés qualitativo e os softwares google forms, excel e word.

O estudo realizado obedeceu os seguintes passos:

1. Validação da problemática;

2. Revisão de literatura;

3. Planejamento e validação do instrumento de pesquisa;

4. Aplicação dos questionários;

5. Tabulação e análise dos resultados;

6. Publicação dos resultados.

A presente pesquisa apresenta contribuições significativas, por conta da avaliação dos resultados da política pública implementada como suporte ao desenvolvimento de novas políticas públicas e o aprimoramento das existentes. Quanto à análise de dados, foi utilizada uma abordagem quali-quantitativa. Quanto aos objetivos, a pesquisa foi exploratória em um primeiro momento e posteriormente descritiva. A técnica de coleta de dados utilizada foi a aplicação de questionário. Segundo Gil (2008), o questionário é uma "técnica de investigação composta por um número mais ou menos elevado de questões apresentadas por escrito às pessoas, tendo por objetivo o conhecimento de opiniões, crenças, sentimentos, expectativas, situações vivenciadas, etc.”.

O questionário desenvolvido contou com perguntas do tipo aberta e do tipo fechada. O instrumento de coleta de dados teve questões de caracterização do respondente e um conjunto de itens medidos na escala de Likert com 5 categorias de medida. As questões que utilizaram a escala de Likert são apresentadas no Quadro 1. As opções da escala variaram entre 1 e 5 , sendo 5 o maior número de concordância e 1 o maior grau de discordância e foram as seguintes: 1. Discordo totalmente, 2. Discordo parcialmente, 3. Nem concordo nem discordo, 4. Concordo parcialmente, 5. Concordo totalmente.

De forma a estimar a confiabilidade do questionário aplicado na pesquisa, mais especificamente das perguntas que utilizaram a escala de Likert, foi utilizado o coeficiente Alfa de Cronbach. De acordo com Hora, Monteiro e Arica (2010), o coeficiente Alfa de Cronbach é uma forma de estimar a confiabilidade de um questionário aplicado em uma pesquisa. O coeficiente mede a correlação entre respostas em um questionário através da análise do perfil das respostas dadas pelos respondentes, tratando-se de uma correlação média entre perguntas. 
Quadro 1. Questões que utilizaram a escala de Likert

\begin{tabular}{|c|c|}
\hline ITEM & QUESTIONAMENTO - ESCALA DE LIKERT \\
\hline 20 & $\begin{array}{l}\text { Busquei emprego em na cidade onde cursei minha graduação ou em cidades } \\
\text { próximas. }\end{array}$ \\
\hline 21 & $\begin{array}{l}\text { Existia emprego na minha área de formação na cidade onde cursei minha } \\
\text { graduação ou em cidades próximas. }\end{array}$ \\
\hline 22 & $\begin{array}{l}\text { Eu gostaria de ter conseguido um emprego na minha área de formação na cidade } \\
\text { onde cursei minha graduação ou em cidades próximas. }\end{array}$ \\
\hline 32 & Concluí o meu curso dentro do prazo previsto. \\
\hline 34 & $\begin{array}{l}\text { Quando ingressei na UFC houve esclarecimentos sobre o perfil e os objetivos do } \\
\text { curso. }\end{array}$ \\
\hline 36 & Esses esclarecimentos foram importantes para que eu continuasse no curso. \\
\hline 37 & Aprendi e compreendi os conteúdos das disciplinas do curso. \\
\hline 38 & Não senti dificuldades em acompanhar as disciplinas no curso. \\
\hline 39 & $\begin{array}{l}\text { Os materiais das disciplinas foram bem preparados e cuidadosamente } \\
\text { transmitidos. }\end{array}$ \\
\hline 40 & Os professores do curso, de uma forma geral, eram dinâmicos e motivadores. \\
\hline 41 & $\begin{array}{l}\text { Os estudantes eram constantemente convidados a compartilhar suas ideias, } \\
\text { questionamentos e conhecimentos durante as aulas. }\end{array}$ \\
\hline 43 & Sempre pensei em permanecer no curso. \\
\hline 46 & Recebi algum tipo bolsa remunerada durante a graduação. \\
\hline 48 & Senti-me preparado para o mercado de trabalho quando me formei. \\
\hline 49 & $\begin{array}{l}\text { O conhecimento adquirido nas disciplinas foi suficiente para garantir o meu bom } \\
\text { desempenho profissional. }\end{array}$ \\
\hline 50 & $\begin{array}{l}\text { Considero que existe forte relação com o que aprendi durante o curso e a } \\
\text { realidade exigida pelo mercado profissional. }\end{array}$ \\
\hline 51 & $\begin{array}{l}\text { Tive que passar por algum treinamento ou requalificação para ingressar ou ao } \\
\text { ingressar no mercado de trabalho. }\end{array}$ \\
\hline 53 & No meu trabalho existem programas de capacitação continuados. \\
\hline 54 & $\begin{array}{l}\text { O curso de graduação concluído me ajudou e ainda me ajuda a construir minha } \\
\text { trajetória profissional. }\end{array}$ \\
\hline
\end{tabular}

Fonte: Pesquisa direta (2016).

Já na análise das questões do tipo aberta, as informações obtidas foram tratadas qualitativamente, através da identificação das respostas mais recorrentes que traziam dados mais significativos. As repostas abertas e fechadas e suas respectivas formas de análise (quantitativa e qualitativa) foram relacionadas para uma análise mais profunda do fenômeno.

A coleta de dados se deu de forma censitária, ou seja, foram aplicados questionários a todos os egressos dos cursos de Tecnologia da Informação (TI) dos campi da UFC em Quixadá e Sobral, o que correspondeu, a 107 indivíduos do primeiro campus e 41 do segundo, totalizando 148 alunos egressos.

O quantitativo de 102 egressos respondeu ao questionário, o que representa cerca de $68,9 \%$ do total de questionários aplicados, sendo 20 respondentes de Sobral e 82 Quixadá. Já a elaboração e aplicação do questionário foi feita através da ferramenta google forms que é uma ferramenta utilizada na internet e disponibilizada pelo site wrwr.google.com.br. O questionário foi enviado aos egressos através de um link específico criado pelo programa, que permitiu que os mesmos pudessem responder as questões. Ao finalizar o preenchimento do questionário os respondentes enviaram as respostas para 
uma base de dados disponível na conta google da pesquisadora. A base de dados é privativa. Os dados foram convertidos para o formato excel.

\section{Análise dos resultados}

A análise dos dados obtidos durante a aplicação do questionário, aos egressos em estudo, passou por testes de confiabilidade e por análises comparativas que se fundamentaram no referencial teórico desta pesquisa. Os dados obtidos com a aplicação do questionário foram transcritos para um arquivo do software excel para Windows, e feita análise de correlação e consistência interna do instrumento, através do cálculo do Coeficiente de precisão Alfa de Cronbach. O valor mínimo aceitável para a confiabilidade de um questionário é o alfa igual ou maior a 0,70 , sendo que o alfa entre 0,60 a 0,75 é considerado moderado e abaixo desse valor a consistência interna da escala utilizada é considerada baixa. De 0,75 a 0,90 é um índice considerado alto e a partir de 0,90 pode-se considerar que há redundância ou duplicação, ou seja, vários itens estão medindo exatamente o mesmo elemento de um constructo (Pinto, 2012, p. 5).

$\mathrm{O}$ quadro 2 mostra os fatores identificados e seus respectivos graus de correlação que variaram entre 0,70 a 0,79, índices considerados aceitáveis para este tipo de escala.

A amostra da pesquisa constituída por 89 alunos do sexo masculino (87,25\%) e 13 do sexo feminino $(12,75 \%)$. Os resultados estão em conformidade com dados do censo da Educação Superior de 2013, os quais revelam que os cursos mais procurados pelo sexo masculino são aqueles das áreas de "Engenharia, Produção e Construção" e "Ciências, Matemática e Computação”, o que pode ser visualizado pelos elevados percentuais de matrículas alcançados, sendo que nas IES públicas, essas áreas representam 66,4\% e $65,2 \%$ das matrículas, respectivamente, e nas IES privadas, $71,5 \%$ ("Ciências, Matemáticas e Computação") e 69,4\% ("Engenharia, Produção e Construção”) (INEP, 2014, p.25).

Quadro 2. Precisão dos fatores extraídos - Alfa de Cronbach

\begin{tabular}{|c|c|c|c|}
\hline FATOR & $\begin{array}{c}\text { AlFA DE } \\
\text { CRONBACH }\end{array}$ & $\begin{array}{c}N^{\circ} \text { DE } \\
\text { QUESTÕES }\end{array}$ & $\begin{array}{l}\text { QUESTÕES DO } \\
\text { FATOR }\end{array}$ \\
\hline 1 - Formação acadêmica & 0,70 & 04 & $37,39,40,41$ \\
\hline 2 - Mercado de trabalho & 0,74 & 03 & $48,49,50$ \\
\hline $\begin{array}{l}\text { 3- Relação entre formação acadêmica e } \\
\text { mercado de trabalho }\end{array}$ & 0,79 & 07 & $\begin{array}{c}37,39,40,41,48 \\
49,50\end{array}$ \\
\hline $\begin{array}{l}\text { 4- Inserção laboral, Mercado de trabalho } \\
\text { regional, Formação acadêmica e } \\
\text { Preparação para o mercado de trabalho }\end{array}$ & 0,70 & 16 & $\begin{array}{c}21,32,34,36,37,38,39 \\
40,41,43,46,48,49,50 \\
53,54\end{array}$ \\
\hline $\begin{array}{l}5 \text { - Correlações diversas com foco em } \\
\text { mercado regional }\end{array}$ & 0,79 & 11 & $\begin{array}{c}21,34,36,37,39,40,41 \\
48,49,50,54\end{array}$ \\
\hline $\begin{array}{l}6 \text { - Correlações diversas com foco em } \\
\text { preparação para o mercado de trabalho }\end{array}$ & 0,76 & 09 & $\begin{array}{c}37,38,39,40,41,48,49 \\
50,54\end{array}$ \\
\hline
\end{tabular}

Fonte: Pesquisa direta (2016).

Como se percebe, a grande área "Computação" tem sido ao longo do tempo muito procurada por pessoas do sexo masculino. Já a idade dos egressos pesquisados se distribui com uma média de 25,62 anos e uma mediana de 25 anos. As idades se concentraram entre 22 e 27 anos, faixa etária que corresponde a $79,2 \%$ da amostra. 
Segundo dados do Censo da Educação Superior, INEP 2014, a idade média de concluintes de curso de graduação é 23 anos.

Tendo em consideração o curso de graduação, foi verificado que a maioria dos egressos se encontra no curso de Sistemas de Informação (53,92\%), seguidos pelos cursos de Engenharia de/da computação (19,61\%), Engenharia de Software (14,71\%) e Redes de Computadores (11,76\%). Com relação ao exercício de atividade remunerada, a partir dos dados apresentados no Gráfico 1, identifica-se que $81,38 \%$ dos egressos exercem atividade remunerada, sendo que $66,67 \%$ destes estão trabalhando na área de sua graduação. 14,71\% estão fora de sua área de formação e 18,63\% não estão exercendo trabalho remunerado. Para observação deste percentual de 18,63\% que não estão trabalhando, observamos dados da Tabela 3 desta pesquisa onde $26,47 \%$ destes egressos afirmaram que o principal motivo para não estarem exercendo atividade remunerada é a condição de estarem estudando pós-graduação com bolsa de estudos, ou seja, dos desempregados nem todos estão em busca de trabalho visto estarem na pós-graduação. Sendo assim, o percentual real de desempregados dos campi de Quixadá e Sobral gira em torno de $12 \%$. Outro dado pesquisa foi com relação ao tempo que os egressos levaram para conseguir o primeiro emprego. $62,74 \%$ dos egressos conseguiram o primeiro trabalho na área de TI até o primeiro ano posterior à formatura, sendo que 33,33\% conseguiram emprego durante a graduação. Há mais uma vez uma parcela significativa da amostra que afirma não ter conseguido emprego na área de TI que representa 33,33\% da amostra.

Segundo os respondentes que não estão exercendo atividade remunerada o principal motivo indicado é a falta de oportunidades no local/região onde moram, 33,35\% (Vide quadro 3).

Quadro 3. Motivo para não conseguir emprego em nenhuma área ou não conseguir emprego na área de formação acadêmica

\begin{tabular}{lc}
\hline $\begin{array}{c}\text { O PRINCIPAL MOTIVO PARA EU NÃO ESTAR EXERCENDO ATIVIDADE REMUNERADA } \\
\text { EM NENHUMA ÁREA OU NÃO ESTAR EXERCENDO ATIVIDADE REMUNERADA NA } \\
\text { MINHA ÁREA DE FORMAÇÃo É: }\end{array}$ & TOTAL \\
\hline $\begin{array}{l}\text { Estou cursando pós-graduação (mestrado/doutorado) com bolsa de estudos. } \\
\text { Estou me dedicando para concursos em outras áreas que não Tecnologia da }\end{array}$ & $26,47 \%$ \\
$\quad \begin{array}{l}\text { Informação. } \\
\text { Estou me dedicando para concursos na minha área. }\end{array}$ & $5,88 \%$ \\
Falta de oportunidade no mercado regional. & $2,94 \%$ \\
Falta de oportunidades no mercado de trabalho onde moro. & $32,35 \%$ \\
Fui aprovado em concurso público, mas não fui convocado. & $2,94 \%$ \\
Me formei recentemente e ainda não encontrei oportunidades. & $2,94 \%$ \\
Melhor oportunidade em outra área. & $8,82 \%$ \\
Motivos particulares. & $5,88 \%$ \\
Procura na área não é respondida pelas empresas contratantes, por exigirem & $2,94 \%$ \\
$\quad$ experiência no cargo. & $2,94 \%$ \\
\hline Tecnólogos não são bem vistos no mercado de trabalho (Muitas vezes vistos como & \\
$\quad$ técnicos). & $100,00 \%$ \\
\hline Total Geral &
\end{tabular}

Fonte: Pesquisa direta (2016). 
É importante se destacar o fato de $26,47 \%$ dos jovens não ter ingressado no mercado de trabalho por estarem dedicados à carreira acadêmica, com bolsa de estudos. De acordo com dados do Censo Iberoamericano de TIC, realizado pela Federação Iberoameicana de Entidades de Tecnologias da Informação (ALETI), apenas 15\% das empresas na região ibero-americana não mantém profissionais com pós-graduação em suas equipes, sendo que as maiores taxas estão perto de 30\% (Argentina, Equador e Paraguai), enquanto no Brasil e na Colômbia essa taxa é de $11 \%$ e 12\%, respectivamente (ALETI, 2015, p.41).

Na área de Tecnologia da Informação, mais precisamente em Ciência da computação, até 2015, o Brasil possuía 73 programas de pós-graduação stricto sensu. Destes, apenas 4 estão no Ceará e se concentram na capital do estado. Nenhuma das universidades citadas e nenhum dos campi da UFC em estudo, Quixadá e Sobral, possuem, atualmente, programas de mestrado ou doutorado na área de TI (UFC, 2016).

Filtramos os dados e selecionamos as respostas dos egressos que não estão atuando na área da formação acadêmica, mas estão exercendo atividade remunerada de alguma forma. A quadro 4 apresenta os motivos mais recorrentes para que estes egressos não atuem em suas respectivas áreas de formação.

Quadro 4. Motivo para exercício de atividade remunerada fora da área de formação acadêmica

\begin{tabular}{|c|c|}
\hline $\begin{array}{l}\text { O PRINCIPAL MOTIVO PARA EU NÃO ESTAR EXERCENDO ATIVIDADE REMUNERADA } \\
\text { (NA MINHA ÁREA DE FORMAÇÃO) É: }\end{array}$ & TOTAL \\
\hline Estou me dedicando para concursos na minha área. & $14,29 \%$ \\
\hline Falta de oportunidade no mercado regional. & $7,14 \%$ \\
\hline Falta de oportunidades no mercado de trabalho onde moro. & $35,71 \%$ \\
\hline Fui aprovado em concurso público, mas não fui convocado. & $7,14 \%$ \\
\hline Melhor oportunidade em outra área. & $21,43 \%$ \\
\hline $\begin{array}{l}\text { Procura na área não é respondida pelas empresas contratantes, por exigirem } \\
\text { experiência no cargo. }\end{array}$ & $7,14 \%$ \\
\hline $\begin{array}{l}\text { Tecnólogos não são bem vistos no mercado de trabalho (Muitas vezes vistos como } \\
\text { técnico). }\end{array}$ & $7,14 \%$ \\
\hline Total Geral & $100 \%$ \\
\hline
\end{tabular}

Fonte: Pesquisa direta (2016).

Nota-se que, assim como os egressos que não estão trabalhando, o maior motivo, $35,71 \%$, para o exercício laboral fora da área de formação acadêmica foi a falta de oportunidades no mercado de trabalho onde moram. Outro fator importante é que $14,29 \%$ dos egressos afirmaram que estavam estudando para concursos na sua área de formação, apesar de ainda exercerem atividade remunerada dentro da área. Para melhor delinear estes dados, questionamos se os egressos estavam cursando ou já haviam cursado pós-graduação. Nesta questão os egressos poderiam escolher mais de uma opção. Obtivemos os seguintes números. 50,98\% dos egressos cursaram ou estão cursando cursos de pós-graduação, sendo que 19,61\% deles já cursaram ou estão cursando mestrado e $20,59 \%$ já cursarem ou estão cursando especialização. Apenas $1,96 \%$ estão no doutorado. Estes índices podem ser motivados pela necessidade constante de atualização que o mercado de TI exige.

Retomando a discussão dos dados da Tabela 2, que identificou como o principal motivo dos egressos não conseguirem emprego ser a falta de oportunidades no mercado 
local/regional. Essa é uma situação bastante recorrente na inserção laboral no Brasil, pois os grandes centros populacionais e econômicos acabam sendo os maiores absorvedores de mão de obra, especialmente de mão de obra qualificada na área de tecnologia.

Os resultados obtidos na pesquisa indicaram uma maior empregabilidade dos egressos pesquisados em Fortaleza, capital mais próxima e maior centro econômico do Estado. De acordo com dados da Câmara Setorial da Cadeia Produtiva de Tecnologia da Informação e Comunicação (CSTIC), da Agência de Desenvolvimento do Estado do Ceará (ADECE), o município de Fortaleza possuía em 2012 cerca de 700 empresas de base tecnológica e 15 instituições de ensino que oferecem cursos de formação profissional em Tecnologia da Informação e Comunicação. Destas, 13 ofereciam cursos de nível superior, 2 de nível técnico e 6 de qualificação profissional. Fortaleza possui, ainda, vários institutos de pesquisas, mas esses números ainda são bem pequenos comparados a outros estados e o setor de TI ainda é bastante desconhecido pela população do estado do Ceará (CSTICS, 2012).

No que diz respeito à localização do setor no território cearense, importante frisar que o Setor de TI cearense está fortemente concentrado na Região Metropolitana de Fortaleza (RMF), embora apresente unidades fabris na Mesorregião dos Sertões Cearenses e na Mesorregião do Cariri. Desta forma, a RMF abriga 86,90\% do número total de estabelecimentos do setor de TI, enquanto o Cariri responde por 5,01\%; e os Sertões, por 2,50\% (CSTIC, 2012). Bem vê-se que o mercado e por conseguinte as oportunidades de trabalho na área de TI se concentram em Fortaleza. Esses índices são percebidos também nas respostas dos egressos de Quixadá e Sobral. Cerca de 40\% dos egressos estão em Fortaleza, 8,82\% estão em outros estados do país e 1,96\% estão em outros países.

Apesar da maior concentração de empregos em Fortaleza, os dados mostram que um percentual significativo de egressos conseguiu emprego na cidade onde se formaram $(22,55 \%)$ e em outras cidades do interior do Ceará (14,71\%). Este fato pode ser um indício positivo de que a realidade das economias regionais está melhorando e a absorção de mão de obra qualificada começa a acontecer também nas cidades mais distantes das capitais brasileiras. Para confirmação deste dado sugere-se um estudo a médio prazo com os egressos destes campi. Será, porém, que esses egressos buscaram trabalho no mercado regional ou eles preferiram se deslocar para outras regiões e estados? O Gráfico 1 mostra que mesmo que não tenham conseguido emprego em economias regionais a maioria dos egressos buscou trabalho na cidade onde concluiu o curso ou em cidades próximas. Cerca de 55\% afirmaram que concordam totalmente ou concordam parcialmente que realizaram esta busca de emprego nas respectivas regiões ondem se formaram.

Conforme apresentado no Gráfico 2, essa procura nem sempre obteve êxito, visto que cerca de $50 \%$ dos jovens que buscaram emprego na região onde concluíram os cursos "discordam totalmente" ou "discordam parcialmente" que existia emprego na área de formação na cidade onde cursaram suas graduações ou em cidades próximas. 


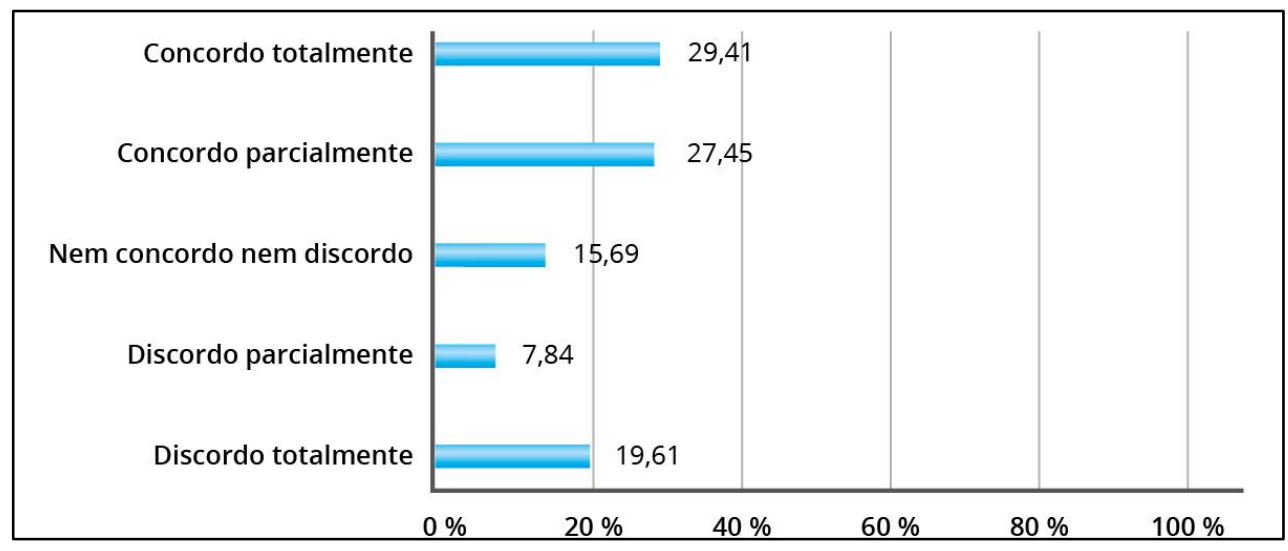

Gráfico 1. Busca por emprego no mercado regional Fonte: Pesquisa direta (2016).

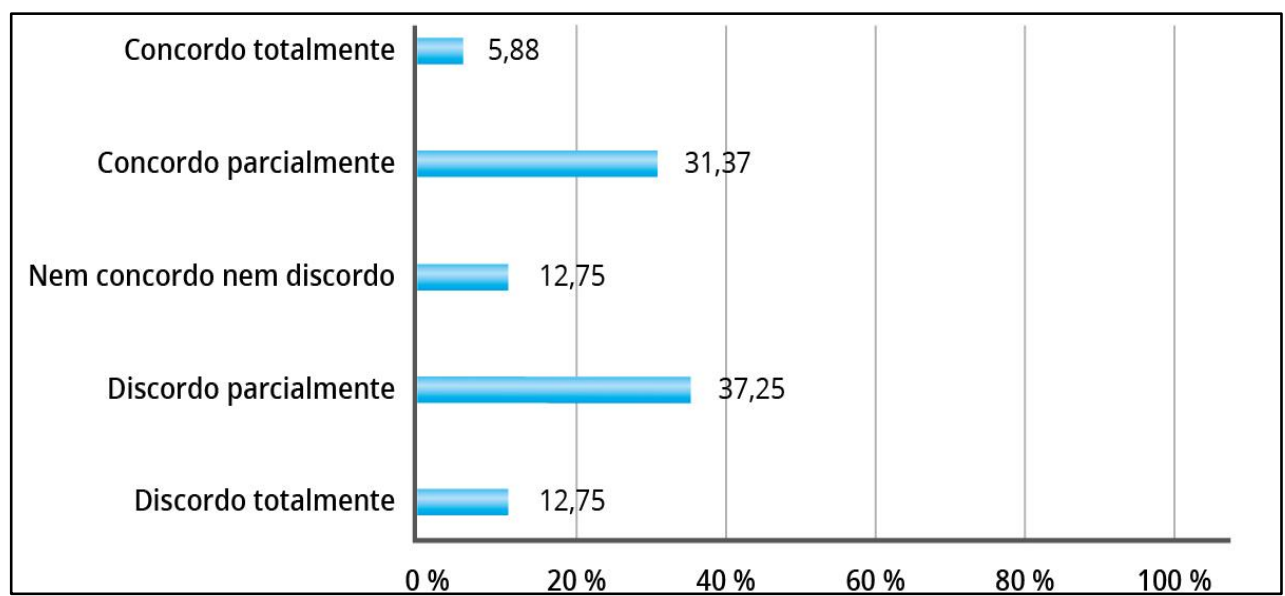

Gráfico 2. Existência de emprego no mercado regional Fonte: Pesquisa direta (2016).

Essa busca se deu pela vontade dos egressos de conseguirem trabalho na região onde concluíram o curso, como é mostrado no Gráfico 3. Cerca de 43\% dos respondentes "concordam totalmente" e mais de $20 \%$ concordam "parcialmente' quando indagados se gostariam de ter conseguido um emprego na área de formação na cidade onde cursaram a graduação ou em cidades próximas.

No que diz respeito aos que estão atuando no mercado de trabalho, identificamos a forma como exercem a atividade, de acordo com a informação apresentada na quadro 5. 


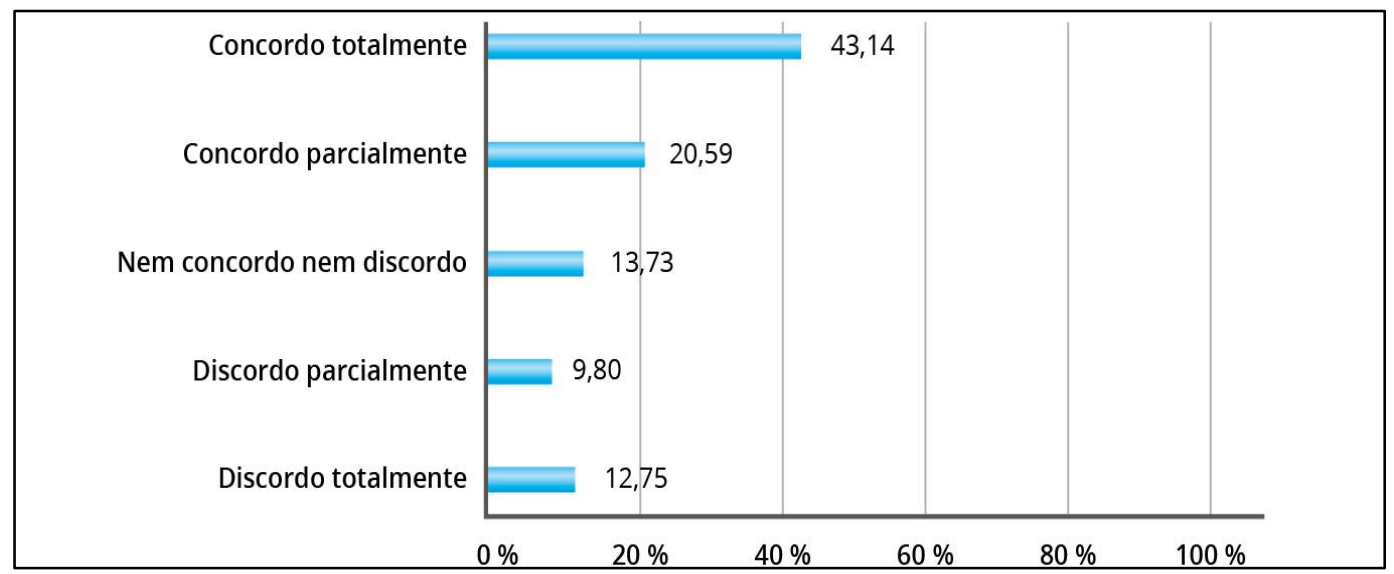

Gráfico 3. Desejo dos egressos de conseguirem emprego no mercado regional. Fonte: Pesquisa direta (2016).

Quadro 5. Forma de exercício laboral dos egressos

\begin{tabular}{lc}
\hline \multicolumn{1}{c}{ EXERÇO MINHA ATIVIDADE PROFISSIONAL DA SEGUINTE FORMA: } & TOTAL \% \\
\hline Não estou trabalhando. & 18,63 \\
Tenho empresa própria. & 3,92 \\
Trabalho como autônomo ou profissional liberal. & 3,92 \\
Trabalho como autônomo ou profissional liberal, Trabalho em empresa privada. & 2,94 \\
Trabalho em empresa privada. & 38,24 \\
Trabalho em empresa/órgão público. & 33,33 \\
Trabalho em empresa/órgão público e empresa privada. & 0,98 \\
\hline
\end{tabular}

Na questão analisada na Tabela 3, o egresso tinha a possibilidade de escolher mais de uma opção, visto que é possível um trabalhador ter mais de um emprego ou exercer mais de uma forma de trabalho. É salutar se observar que a maioria dos egressos está exercendo atividades em empregos formais, principalmente no setor público e no privado. Este dado representa cerca de $70 \%$ da amostra. Além do percentual que não está trabalhando que representa cerca de $18 \%$ temos os egressos que exercem atividade por conta própria (autônomo ou liberal) e os egressos que possuem empresas. Ambos representam 3,92\%. Observa-se ainda que alguns egressos exercem mais de um tipo de atividade, conciliando atividades de forma autônoma com atividades em empresas privadas, $2,94 \%$, ou em órgãos públicos com atividades em empresas privadas, 0,98\%.

Ainda sobre os egressos que conseguiram emprego, investigamos, conforme mostrado na quadro 6, a forma como essa inserção laboral ocorreu.

Como pode-se observar, a maioria dos egressos (cerca de 50\%) participaram de processos seletivos e em torno de $15 \%$ dos mesmos atuam como concursados no setor público. Um dado relevante é que durante os estágios obrigatórios para a graduação, um percentual representativo dos egressos, cerca de 10\%, conseguiu ser efetivado nas empresas ou instituições onde estagiaram. Há ainda casos de egressos que atuam de forma autônoma e os que abriram seus próprios negócios. A pergunta foi formulada com questões fechadas de múltipla escolha e com o campo "outros" que permitiu aos respondentes 
acrescentarem outras opções. Sugiram, então egressos que afirmaram que conseguiram trabalho através de congressos com premiações.

Quadro 6. Forma de obtenção do emprego atual

\begin{tabular}{lc}
\hline \multicolumn{1}{c}{ OBTIVE MEU EMPREGO ATUAL: } & TOTAL \% \\
\hline Abri minha própria empresa. & 2,94 \\
Fui efetivado na instituição/organização onde estagiei. & 9,80 \\
Ganhei um prêmio de melhor trabalho em um congresso e uma vaga na empresa. & 0,98 \\
Ganhei uma vaga de trainee no prêmio do Congresso Infobrasil. & 0,98 \\
Já trabalhava em empresa própria. & 0,98 \\
Não estou empregado. & 14,71 \\
Por meio de concurso público. & 15,69 \\
Por seleção de currículo. & 27,45 \\
Processo seletivo aberto ao público. & 25,49 \\
Trabalhando autônomo, criando jogos para computador. & 0,98 \\
\hline
\end{tabular}

Fonte: Pesquisa direta (2016).

Com relação ao cargo que exercem no mercado de trabalho as questões de número $24 \mathrm{e}$ 25 perguntaram qual o primeiro cargo na área de TI que o egresso teve e qual o cargo atual. Alguns dados interessantes puderam ser observados no quadro 7, o qual mostra os cargos de TI mais citados. Dentre todos os que mais aparecem são cargos de analistas dos mais diversos, tais como: analista de qualidade, de testes, de suporte em redes, de sistemas, de tecnologia da informação, entre outros. Dentre estes, o cargo que mais é referido é o de analista de sistemas.

Já os cargos de gestão ou coordenação são poucos no primeiro emprego e têm aumento em empregos atuais. No tocante a faixa salarial dos que estão exercendo atividade remunerada obtemos índices, na pergunta 26, que variaram entre "não possui renda" até "possuo renda acima de 6 mil reais". Os índices salariais são apresentados no Gráfico 4.

Quadro 7. Cargos dos egressos na área de TI

\begin{tabular}{cccc}
\hline $\begin{array}{c}\text { QTDE PRIMEIRO } \\
\text { EMPREGO }\end{array}$ & CARGo & $\begin{array}{c}\text { QTDE EMPREGO } \\
\text { ATUAL }\end{array}$ & CARGO \\
\hline 31 & Analistas (diversos) & 31 & Analistas (diversos) \\
13 & Analista de sistemas & 14 & Analista de sistemas \\
15 & Desenvolvedor & 7 & Desenvolvedor \\
9 & Professor & 10 & Professor \\
9 & Estagiário & 0 & Estagiário \\
3 & Bolsista & 2 & Bolsista \\
2 & Coordenador & 6 & Coordenador/gerente \\
\hline
\end{tabular}

Fonte: Pesquisa direta (2016).

Com relação a faixa salarial dos egressos pesquisados, os dados revelam que o maior percentual recebe até $\mathrm{R} \$ 3.000,00$, sendo que somados os percentuais acima de $\mathrm{R} \$ 3.000,00$, temos que cerca de $25 \%$ dos egressos recebem salários ou rendimentos entre $\mathrm{R} \$ 3.000,00$ e $\mathrm{R} \$ 6.000,00$. Aproximadamente $5 \%$ dos egressos tem rendimentos superiores a $\mathrm{R} \$ 6.000,00$.

No que diz respeito a renda dos profissionais de Tecnologia da Informação, a empresa de recrutamento de pessoal CATHO divulgou, em 2014, que a média salarial na área de TI, 
consideradas as posições iniciais, como estágios, até cargos executivos, em diversos cargos. No cargo que tem a mais baixa remuneração que é o de qualidade de software o salário médio para graduados é $\mathrm{R} \$ 3.204,21$. Já o cargo que tem o salário médio maior é o de Arquitetura de Informação que, para um profissional com graduação, paga em torno de $\mathrm{R} \$ 5.800,00$. Os egressos de Quixadá e Sobral também estão em nível salarial bem próximo a este valor considerando que a pesquisa trata de renda média que constitui tanto os salários mais baixos, como os salários mais altos desta categoria de trabalho.

$\mathrm{Na}$ última pergunta, número 27, solicitou-se que os egressos citassem as maiores dificuldades que encontraram ou ainda encontram para o ingresso no mercado de trabalho. As respostas foram codificadas numa linha crescente que foi do código R1 ao R102, equivalentes à resposta 1 e resposta 102, respectivamente, ou seja, cada umas das 102 respostas recebidas receberam codificação relativa ao seu número na lista de respondentes. Esse código será usado em todas as análises de perguntas abertas.

As narrativas dos alunos nesta questão trouxeram diversas afirmações e aspectos que enriquecem e reafirmam o estudo feito até aqui. Dentre alguns deles, destacam-se: i) " As empresas exigem experiência" (R1, R8, R9, R12, R15, R20, R24, R52, R76, R85, R98); ii) "Poucas empresas de TI na região" (R40, R53, R56, R58, R66, R79 ); iii) "Falta de formação para o mercado de trabalho" (R41, R83); iv) "Baixos salários" (R25, R2, R32, R46); Em contraponto, existiram também respostas que afirmaram não ter tido dificuldade em conseguir emprego v) "Não encontrei dificuldades." (R4, R10, R19, R34, R54, R57, R64, R65, R70, R86).

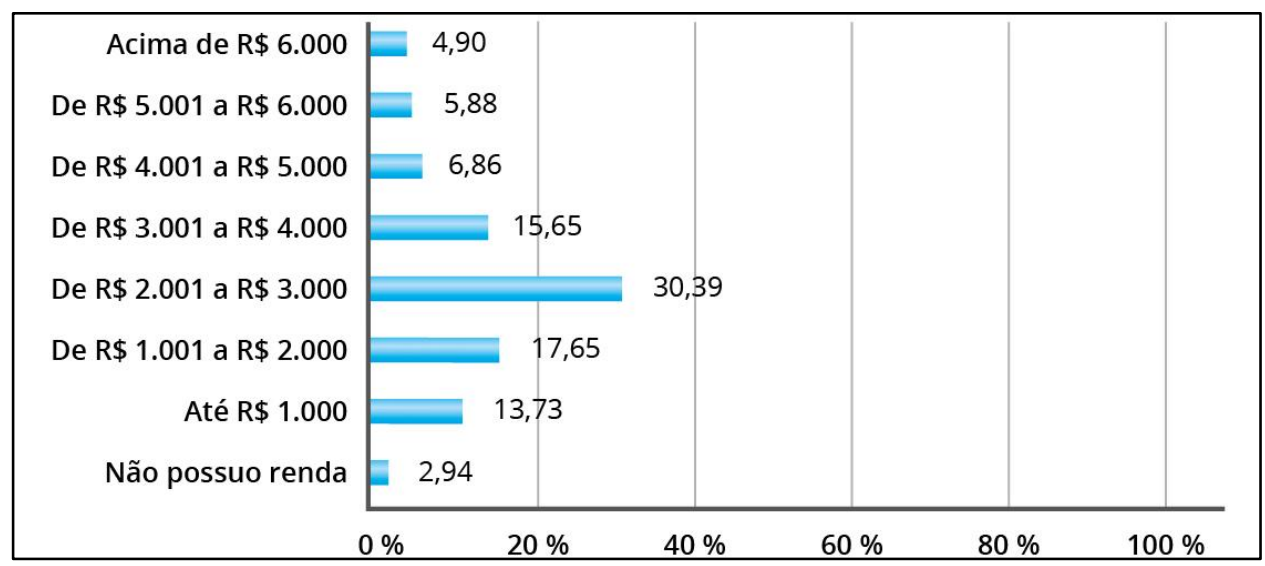

Gráfico 4. Faixa salarial do egresso

Fonte: Pesquisa direta (2016).

Os egressos do campus da UFC em Quixadá tratam bastante da questão de escassez de empregos no mercado regional. A R44, por exemplo, disse que "Para os alunos de TI formados nos campi do interior, as grandes oportunidades estão nos grandes centros urbanos [...] Infelizmente não existe mercado de TI no interior, algumas cidades como Quixadá, até possuem empresas de TI, mas estas não oferecem bons salários e ambiente de trabalho adequado". Já a R15 relatou que "O mercado não absorve bem os recémformados e o mercado em Quixadá é escasso”. Na mesma tendência, a R35 citou que existe "Carência de empresas da área de TI na região do Sertão Central, pois a grande maioria dessas empresas estão centradas na capital do estado". 
Os egressos de Sobral também citaram a falta de oportunidades no mercado regional. Vejamos alguns casos. A R102 cita "Poucas vagas em empresas privadas na região de Sobral”. Já a R95 relata que em Sobral os profissionais de TI não são valorizados, os salários oferecidos são péssimos e o reconhecimento é quase nenhum". A R91 diz que "O mercado de trabalho da cidade (Sobral) em que o curso está localizado é muito fraco. [ ...] Quem está disposto a sair, consegue encontrar colocação no mercado mais rapidamente".

A R4 citou "A falta de oportunidades de estágio na região (Quixadá)", informação ratificada com questões como a R15 "Por não ter tido oportunidade de trabalhar durante a graduação, terminei o curso sem experiência no mercado (somente estágio na própria UFC)”. A R20 citou o caso da falta de empresas de TI em Quixadá da seguinte forma "Em Quixadá não tem muitas empresas para que os alunos possam estagiar". Outros respondentes também citaram a falta de estágio em empresas ou utilizaram o termo "estágio na própria UFC. Este é um ponto muito relevante, pois como verificamos que existem poucas empresas da área de Tecnologia da Informação nos mercados regionais em estudo, as oportunidades de trabalharem na área se tornam escassas e consequentemente as oportunidades de estágio, inclusive para estágio obrigatório dos alunos em formação ficam comprometidas.

Fica perceptível que há muitas dificuldades de inserção nos mercados regionais, especialmente pela escassez de empresas da área de Tecnologia da Informação no interior do estado. Esta percepção coaduna com Rolim (2009), que enfatiza a necessidade de fomento aos atributos regionais para que possam ser atrativos para que empresas se instalem com condições razoáveis de competitividade e consequentemente haja a geração de empregos e absorção de mão de obra qualificada, ou seja, se não há um ambiente regional favorável com incentivos para implantação de empresas, a mão de obra qualificada não terá condição de se estabelecer e permanecer nesta região e a geração de novos postos de trabalho permanece escassa.

Os dados sobre mercado de trabalho se atualizam continuamente e as correlações e comparações são muito importantes para que se tenha um retrato de um grupo ou de uma categoria de profissionais, como é o caso da TIC.

\section{Conclusão}

O presente trabalho avaliou a situação da inserção laboral de egressos de cursos superiores da área de TI da Universidade Federal do Ceará. A pesquisa envolveu uma triangulação entre revisão de literatura, observação e aplicação de questionários.

Constatou-se durante a revisão de literatura, especialmente em Rolim (2009) a importância das universidades para o desenvolvimento das economias regionais, qualificação dos trabalhadores e geração de emprego. Viu-se também que as relações de trabalho estão mudando a cada dia e que a demanda de profissionais de Tecnologia da Informação é grande, mas ainda existem muitas lacunas na qualificação dos profissionais e na própria rede mercadológica que dificultam o acesso ao trabalho, principalmente em mercados regionais, os quais não recebem muitos incentivos para o crescimento econômico, principalmente na área de TI e, por conseguinte, os profissionais acabam sendo absorvidos em grandes centros urbanos, especialmente nas capitais brasileiras. 
Na pesquisa aplicada a 102 egressos dos campi da UFC no interior, pôde-se observar grande busca de qualificação em nível de pós-graduação, tanto que 26,47\% afirmaram, não ter conseguindo emprego na área de formação por estarem cursando mestrado ou doutorado com bolsa de estudos, o que denota a necessidade de qualificação constante dos profissionais da área de TI. Observou-se também que parte significativa dos egressos está inserida no mercado de trabalho, $75 \%$, sendo que $15 \%$ destes não atuam na área de formação. Verificou-se ainda que parte dos jovens conseguiu emprego na cidade ou região onde se formou, cerca de $32 \%$, mas a grande maioria acabou se deslocando para Fortaleza e região metropolitana, 39,22\%, outros estados, $8,82 \%$ ou até outros países, $1,96 \%$, apesar de afirmarem que gostariam de trabalhar no mercado regional, $43,14 \%$.

Existe uma necessidade de se criar políticas públicas que possibilitem a inserção desses alunos em empreendimentos no interior dos estados brasileiros, com a posterior avaliação de suas consequências (Andriola, 1999). Os resultados desta pesquisa indicaram uma dificuldade de inserção laboral dos egressos nos mercados regionais das regiões onde se localizam os campi da UFC em Quixadá e Sobral, acredita-se que deve haver maior fomento à criação de Pólos de Tecnologia da Informação no estado do Ceará (foco da pesquisa), com pontos no interior do estado onde exista a absorção de profissionais que estão sendo qualificados e, por consequência significativa contribuição com a formação destes jovens, especialmente em estágios, aulas práticas e/ou visitas técnicas, etc. Sugere-se a integração política da atuação da Universidade com outros órgãos dos governos a nível federal, estadual e municipal, visando uma melhoria dos resultados a partir de um alinhamento de ações governamentais.

Considera-se muito importante que o governo do estado e as prefeituras municipais das cidades que possuem cursos de graduação na área de Tecnologia da Informação contribuam para a melhoria da formação oferecida e para o desenvolvimento regional destas áreas. Incentivos municipais para instalação de empresas de tecnologia nas cidades do interior através de, por exemplo, cessão de áreas imobiliárias e redução de impostos são primordiais para que as regiões se tornem atrativas para empresas dos mais variados ramos de tecnologia. Acredita-se, também, que a própria universidade pode exercer um papel mais contundente neste trabalho de incentivo de crescimento dos mercados regionais e dos polos de tecnologia, sendo uma incentivadora e articuladora de propostas como essas.

A partir dos resultados identificados, foi identificado que a maioria dos egressos não conseguiu emprego nos mercados regionais. Em suas respostas abertas, eles citam essa falta de oportunidades, apesar do desejo se conseguirem emprego nestes mercados. Foi identificado ainda que os egressos conseguiram empregos em grandes centros urbanos.

Apontar os aspectos frágeis observados na avaliação da inserção laboral de egressos não representa a ideia de considerá-lo como falho, mas, sobretudo, que se faz necessário pensar em medidas corretivas voltadas para o atendimento das expectativas identificadas. Além disso, “[...] uma avaliação deve ter flexibilidade suficiente para atender à diversidade dos interesses das suas várias audiências, com as expectativas das mais diversas possíveis" (Vianna, 2000, p.75).

Entre as ameaças à validade da presente pesquisa, pode-se citar a dificuldade de generalização de resultados, pelo fato do estudo de caso ter sido realizado em uma instituição de ensino superior. Apesar das limitações, os resultados se apresentaram 
promissores, contribuindo para subsidiar o processo de formação para a inserção laboral efetiva de egressos de cursos da área de TI.

\section{Referências}

Aparicio, M., Rodriguez, G. e Rena, M. (2016). Empleabilidad, Profesiomalización y Competencias Socilaes ¿Qué rol juega la Universidad?, Revista GUAL, 9(4), 239-254. https://doi.org/10.5007/1983-4535.2014v9n4p239.

Andriola, W. B. (1999). Evaluación: La vía para la calidad educativa. Ensaio: Avaliação e Políticas Públicas em Educação 7(25), 355-368.

Andriola, W. B. (2011). Doze motivos favoráveis à adoção do Exame Nacional do Ensino Médio (ENEM) pelas Instituições Federais de Ensino Superior (IFES). Ensaio: Avaliação de Políticas Públicas em Educação, 19, 107-126.

Andriola, W. B. (2014). Estudo de egressos de cursos de graduação: subsídios para a autoavaliação e o planejamento institucionais. Educar em Revista, 54, 203-220.

Andriola, W. B. e Suliano, D. C. (2015). Assessment of social impacts resulting from the internalization of the Universidade Federal do Ceará (UFC). Revista Brasileira de Estudos Pedagógicos, 96(243), 282-298.

Associação Brasileira de Empresas de Tecnologia da Informação e Comunicação - BRASSCOM. (2011). O Brasil como player global. São Paulo: Autor.

Bisquerra, R. (2004). Metodología de la Investigación Educativa. Madrid: Editorial la Muralla.

Botello Álvarez, J., Chaparro Salinas E. M. e Reyes Pérez D. E. (2015). Estudio de la Satisfacción de los Estudiantes con los Servicios Educativos brindados por Instituciones de Educación Superior del Valle de Toluca. REICE. Revista Iberoamericana sobre Calidad, Eficacia y Cambio en Educación, 13(2), 5-26.

Brasil: Ministério da Educação. (2012). Análise sobre a expansão das universidades federais 2003 a 2012. Brasília: Autor.

Brasil: Ministério da Educação. (2013). Censo da educação superior. Brasília: Autor.

Brasil: Ministério da Educação. (2007). Decreto $n^{\circ}$ 6.096, de 24 de abril de 2007. Institui o Programa de Apoio a Planos de Reestruturação e Expansão das Universidades Federais - REUNI. Brasília: Autor.

Câmara Setorial da Cadeia Produtiva de Tecnologia da Informação e Comunicação - CSTIC. (2012). Polo de Tecnologia da Informação e Comunicação (Fortaleza, cidade competitiva). Fortaleza: Autor.

Castells, M. (1999). A sociedade em rede. São Paulo: Paz e Terra.

Catho. (2014). Na semana do Dia da Informática, Catho aponta os cargos mais bem remunerados da área. São Paulo. Recuperado de http://www.catho.com.br/institucional/2014/08/nasemana-do-dia-da-informatica-catho-aponta-os-cargos-mais-bem-remunerados-daarea/\#topo

Chaui, M. (2003). A universidade pública sob nova perspectiva. Revista Brasileira de Educação, 24, $5-15$.

Cisco Systems. (2015). Habilidades em redes e conectividade na América Latina. Brasília: Autor. 
Federação Iberoamericana de Entidades de Tecnologias da Informação - ALETI. (2015) Rumbo a un censo iberoamericano TIC. Brasília: Autor. Recuperado de http://www.mbi.com.br/mbi/biblioteca/relatorios/2015-07-aleti-censo-tic-relatorio2015/2015-07-ALETI-Estudio-Sector-TIC-Informe-2015.pdf

Garcés C. R. e Riquelme V. C. (2014). Empleabilidad, Ingesos $\Upsilon$ Brechas: Un Análisis Comparativo de los Procesos de Imserción Laboral. Chile: Orientación y Sociedad.

Gil, A. C. (2008). Métodos e técnicas de pesquisa social. São Paulo: Atlas.

Hora, H. R. M., Monteiro, G. T. R. e Arica, J. (2010). Confiabilidade em questionários para qualidade: um estudo com o coeficiente alfa de Cronbach. Produto \&̊ Produção, 11(2), 85103.

Internet Data Center. (2014). Pesquisa nacional por amostra de domicílios contínua. Rio de Janeiro. Recuperado de ftp://ftp.ibge.gov.br/Trabalho_e_Rendimento/Pesquisa_Nacional_por_Amostra_de_Do micilios_continua/Notas_metodologicas/notas_metodologicas.pdf

INEP. (2014). Censo da educação superior: notas estatísticas. Brasília: Autor.

Lima, A. S. e Andriola, W. B. (2013). Avaliação de Práticas Pedagógicas Inovadoras em Curso de Graduação em Sistemas de Informação. REICE. Revista Iberoamericana Sobre Calidad, Eficacia y Cambio en Educación, 11(1), 104-121.

Lima, A. S., Andriola, W. B. e Tavares, W. A. (2015). Melhorando o processo de ensino e aprendizado em cursos de graduação na área de computação por meio da utilização de edublogs. Revista Ibero-Americana de Estudos em Educação, 10, 816-841.

Macedo, M. C. B. (2011). O mercado de trabalho em Tecnologia da Informação: a inserção profissional dos desenvolvedores de software. Dissertação (Mestrado em Sociologia). Porto Alegre: Instituto de Filosofia e Ciências Humanas, Universidade Federal do Rio Grande do Sul.

Miranda, C. S., Pazello, E. T. e Lima, C. B. (2015). Egressos como instrumento de avaliação institucional: uma análise da formação e empregabilidade dos egressos da FEA-RP/USP. Revista GUAL, 8(1), 298-321. https://doi.org/10.5007/1983-4535.2015v8n1p298

Pinto, G. A. e Arica, J. R. (2012, outubro). O uso do coeficiente alfa de Cronbach nos resultados de um questionário para avaliação dos serviços no setor de transporte urbano por ônibus. Comunicaçao apresentada no Encontro Nacional de Engenharia de Produçã, Universidade Bento Gonçalves, Rio Grande do Sul. Recuperado de http://www.abepro.org.br/biblioteca/enegep2012_tn_sto_158_924_19802.pdf

Rocha, E. C. F. (2015). Qualificação e reconhecimento de profissionais de Sistemas de Informação. Aviso publicado em Proceedings of Brazilian Symposium on Information System (pp. 595-602). Goiânia: LBD/UFMG. Recuperado de http://www.lbd.dcc.ufmg.br/colecoes/sbsi/2015/o80.pdf

Rolim, C. e Serra M. (2009). Instituições de Ensino Superior e desenvolvimento regional: o caso da Região Norte do Paraná. Revista de Economia, 35(3), 87-102.

Sindicato das Empresas de Informática. (2015). Apesar da crise, número de contratações supera demissões no setor de TI. Recuperado de http://www.sindinfo.com.br/2015/index.php/noticias/item/1669-apesar-da-crisenumero-de-contratacoes-supera-demissoes-no-setor-de-ti

Universidade Federal do Ceará. (2012). Pró-Reitoria de Planejamento. PDI: Plano de Desenvolvimento Institucional: 2013-2017. Fortaleza: Autor. Recuperado de 
http://www.ufc.br/images/_files/a_universidade/plano_desenvolvimento_institucional/ pdi_ufc_2013-2017.pdf

Vianna, H. M. (2000). A avaliação Educacional: teoria-planejamento-modelos. São Paulo: IBRASA.

Vinogradov, S. A. (2017). Measuring of the Labour Market Success of Graduates of the Szentisván University. Management, Organizations and Society, 3, 41-52. https://doi.org/10.18515/dBEM. M2017. no1.

\section{Breve CV dos autores}

\section{Maria Simone Mendes Nunes}

Mestranda em Políticas Públicas e Gestão da Educação Superior pela Universidade Federal do Ceará, Graduação em Letras-Português e especializações em Educação a Distância e em Gestão Pública, ambas pela Universidade Estadual do Ceará. Experiência na área de gestão administrativa e qualificação para o trabalho, tendo exercido funções de supervisão, coordenação e monitoramento de projetos de qualificação social e profissional para juventude, além de experiências na área de ensino. Atua como Assistente em Administração na Universidade Federal do Ceará - Campus Quixadá. Email: simone.mnunes@gmail.com

\section{Alberto Sampaio Lima}

Doutor em Engenharia de Teleinformática pela Universidade Federal do Ceará. Mestre em Informática Aplicada pela Universidade de Fortaleza. Bacharel em Ciência da Computação pela Universidade Estadual do Ceará. Tem experiência na área de Ciência da Computação, com ênfase em Arquitetura de Sistemas de Computação, atuando principalmente nos seguintes temas: Gestão de Tecnologia da Informação e Comunicação, Redes de Computadores, Engenharia de Software, Novas Tecnologias na Educação, Avaliação da Educação. Professor do Mestrado Profissional em Políticas Públicas e Gestão da Educação Superior da Universidade Federal do Ceará (POLEDUC). Email: albertosampaio@ufc.br

\section{Wagner Bandeira Andriola}

Possui graduação em Psicologia pela Universidade Federal da Paraíba (1990), especialização (lato sensu) em Psicometria pela Universidade de Brasília (1992), mestrado em Psicologia pela Universidade de Brasília (1993 - bolsista CNPq) e doutorado em Filosofia e Ciências da Educação pela Universidad Complutense de Madrid (2002 - bolsista CAPES). Atualmente é Professor Associado da Universidade Federal do Ceará (UFC), Coordenador de Avaliação Institucional (UFC), Editor-Chefe da Coleção Temas em Avaliação Educacional, do Programa de Mestrado e Doutorado em Educação (UFC) e Bolsista de Produtividade em Pesquisa (CNPq). Tem experiência nas áreas de Psicologia e de Educação, com ênfase em Avaliação de Sistemas, Instituições, Planos e Programas Educacionais, atuando principalmente nos seguintes temas: avaliação institucional, avaliação psicológica, psicometria e avaliação de programas e projetos sociais. Consultor ad-hoc da Revista Ensaio: Avaliação de Políticas Públicas em Educação (CESGRANRIO), da Revista Psicologia: Reflexão e Crítica 
(UFRGS), da Revista de Avaliação Psicológica (IBAP) e da Revista Psicologia: Teoria e Pesquisa (UnB); Consultor ad hoc do Conselho Nacional de Desenvolvimento Científico e Tecnológico (CNPq), da Coordenação de Aperfeiçoamento de Pessoal de Nível Superior (CAPES), da Fundação Cearense de Apoio Científico e Tecnológico (FUNCAP). Membro da Diretoria da Associação Nacional de Avaliação Educacional (ABAVE - Gestões 2006/2007 e 2008/2009), da Red Iberoamericana de Investigación sobre Cambio y Eficacia Escolar (RINACE) e do Grupo de Trabalho para Elaboración de Estandares y Evaluación del Programa de Promoción de la Reforma Educativa de América Latina y el Caribe (PREAL). Ex-bolsista de Desenvolvimento Científico e Regional (DCR) do CNPq. Email: w_andriola@ufc.br

\section{João Ferreira de Lavor}

Doutor em Educação Brasileira pela UFC (2014). No Doutorado trabalhou com avaliação educacional no núcleo NAVE/UFC, Mestrado em Desenvolvimento e Meio Ambiente pela Universidade Federal do Ceará (2003), possui graduação em Pedagogia Magistério pela Universidade Estadual do Ceará (2000) Graduação em Ciências Contábeis pela Universidade Estadual do Ceará - UECE(2006) e graduando em Direito pela UNIFOR. É atualmente professor Adjunto da Universidade Federal do Ceará Campus Quixadá (CE). Email: joaodilavor@gmail.com

\section{Francisco Erivelton Fernandes de Aragão}

Mestre em Ciências da Computação pela Universidade Federal do Ceará (2002). Possui graduação em Estatística pela Universidade Federal do Ceará (1986). Tem experiência na área de Ciência da Computação, com ênfase em Teoria da Computação. Atuando principalmente nos seguintes temas: Lógica e Probabilidade, Raciocínio Automático. Email: aragaoufc@gmail.com 